\title{
THE ROLE OF WORKING HOURS ON WORK-LIFE CONFLICT
}

\author{
DOI: 10.17261/Pressacademia.2018.920 \\ PAP- V.7-2018(73)-p.376-380
}

\section{Isik Cicek ${ }^{1}$, Aysen Gezici}

${ }^{1}$ Alanya Alaaddin Keykubat University, Alanya, Turkey. cicekis@yahoo.com, ORCID: 0000-0003-0870-3811

${ }^{2}$ Alanya Alaaddin Keykubat University, Alanya, Turkey. aysengezici@hotmail.com, ORCID: 0000-0002-7397-1479

To cite this document

Cicek, I., Gezici, A. (2018). The role of working hours on work-life conflict. PressAcademia Procedia (PAP), V.7, p.376-380.

Permemant link to this document: http://doi.org/10.17261/Pressacademia.2018.920

Copyright: Published by PressAcademia and limited licenced re-use rights only.

\section{ABSTRACT}

Purpose- In today's increasingly competitive conditions, businesses are pushing more and more to transform assets into higher value added assets and to maintain their core competencies on a sustainable scale. In this context, institutional abilities will have a close semantic relationship with the characteristics of the characteristics of the assets. With an increasingly recognized approach, intellectual capital sees businesspeople as one of the most important assets they possess, and they can redefine the roles that employees can take to maintain their competitive position, depending on the changing internal and external environmental conditions. In this sense, a situational variable faced by employees is the workload and the work / private life conflict that will arise therefrom. The main purpose of this work is to perceive the workload in a working dimension and to measure how often the work / private life conflict will be experienced at work due to the weekly working hours measured objectively.

Methodology- In the study, 303 participants were selected through convenience-sampling method and the working hours data of 129 participants could have been obtained. Business-family conflict was measured by 10 -item scales that developed by Netenmayer through two subscales that work-family and family-work.

Findings- Work intensity was measured with using 4 items of scale developed by Karasek (1990). Correlation and regression analysis were performed after the normality tests of the data.

Conclusion- According to research findings, there was no explanatory effect of working hours in the experience of work-private life conflict and the perceived workload was positive for both sides of the conflict.

Keywords: Business-private life conflict, work intensity, working hours, job demands.

JEL Codes: M10, M12, M14

\section{IŞ-ÖZEL HAYAT ÇATIŞMASININ ORTAYA ÇIKMASINDA ÇALIŞMA SAATLERININ ROLÜ}

\section{ÖZET}

Amaç- Günümüzün artan rekabet koşulları, işletmeleri varlıkları daha yüksek düzeyde katma değere dönüştürmeye, temel yetkinliklerini sürdürülebilir boyutta korumaya daha çok itmektedir. Bu bağlamda, kurumsal yetenekler varlıkların karakteristikleri özellikleri ile yakın anlamsal ilişki gösterecektir. Gittikçe artan önemde kabul gören bir yaklaşımla entelektüel sermayede, işletmeler çalışanlarını sahip oldukları en önemli varklıklardan biri olarak görmekte, rekabetçi konumlarını sürdürebilmelerinde çalışanların üstlenecekleri rolleri değişen iç ve dış çevre şartlarına bağlı olarak yeniden tanımlayabilmektedirler. Bu açıdan çalışanların karşı karşıya kaldıkları bir durumsal değişken iş yükü ve ona bağlı olarak ortaya çıkacak iş/özel hayat çatışmasıdır. İ̧̧ yükünün çalışan boyutunda algısal bir değerlendirilmesi ve objektif olarak ölçümlenecek haftalık çalışma saatine bağlı olarak iş/özel hayat çatışmasının işgörenlerce ne derecede deneyimleneceğini ölçümlemek bu çalışmanın temel amacıdır.

Yöntem- Çalışmada kolayda örnekleme yolu ile 303 katılımcı seçilmiş, bu katılımcıların 129'unun çalışma saatleri verisi elde edilebilmiştir. İş-aile çatışması Netenmeyer vd. (1996) tarafından geliştirilen 10 maddelik ölçek ile iş-aile ve aile-iş olmak üzere iki alt boyutta ölçümlenmiştir.

Bulgular- İş yoğunluğu ise Karasek (1990) tarafından geliştirilen ölçeğin 4 maddesi kullanılarak ölçümlenmiştir. Verilerin normallik sınamalarının ardından korelasyon ve regresyon analizi yapılmıştır.

Sonuç- Araştırma bulgularına göre iş-özel hayat çatışmasının deneyimlenmesinde çalışma saatlerinin açıklayıcı bir etkisi ortaya çıkmamış, çalışanlarca algılanan işyoğunluğu çatışmanın her iki yönü için olumlu bir etki göstermiştir.

Anahtar Kelimeler: İş-özel hayat çatışması, iş yoğunluğu, çalışma saatleri, iş talepleri.

JEL Kodları: M10, M12, M14 


\section{GiRiş}

iş Talepleri, çalışma ortamında mevcut iş yükü talepleri gibi stres kaynaklarını (stresör) ölçen bağımsız bir değişkene "iş talepleri" denir (Karasek Jr, 1979, s. 287). Iş talepleri iş yoğunluğu ve çalışma saatleri olarak iki şekilde açıklanmıştır. İş yoğunluğu, Çalışanların belli bir süreye yetişmesi gereken işleri kıııtlı zaman altında yaparak çalışması iş yoğunluğunun bir türü olarak karşımıza çıkmaktadır (Soysal, 2009, s. 20-21). Iş̧ yoğunluğu, genel olarak iki şekilde gerçekleşebilir. Illk olarak niceliksel (kantitatif) iş yoğunluğu; ikincisi ise niteliksel (kalitatif) iş yoğunluğudur (Eroğlu, 2000, s. 322 - 323; Cam, 2004, s. 3). Niceliksel iş yoğunluğu, bir çalışanın yapacağı belirli bir iş için "zamanın yetersizliği", sınırı bir zamanda yapılacak "çok farkı işlerin olması" ile "yapılacak işlerin fiziki olarak ağır ve yorucu olması" şeklinde açıklanabilir. Niteliksel iş yoğunluğu ise yapılacak olan işten kaynaklı nitelikler ile işi yapacak olan çalışanın sahip olduğu nitelikler arasında, bir uyumsuzluğun olması durumudur. Bu bağlamda, işi yapacak olan çalışan işin gerektirdiği "bilgiye, yeteneğe ve kişisel özelliklere" tam olarak sahip olmadığı durumda, bu iş kendisi için zor gelecektir ve bu durum onu ve çevresini etkileyecektir. Çalışanların yoğun bir tempoda çalışmaları ve sürekli bir iş yapma halinde olmaları çalışanları zaman konusunda sıkıntıya düşürebilmektedir. Bunun yanında Her gün iş yoğunluğu altında çalışmak, çalışanda yorgunluk, tükenmişlik hissi ve stres oluşturabilmektedir (Soysal, 2009, s. 20-21). Yoğunlaştıııımış İ̧̧ Haftası, Çalışmalarda "denkleştirme yöntemi" olarak da ifade edilen, 4857 SK ile mevzuata dâhil edilmiş yeni bir esnek çalışma türüdür. 4857 SK.m.64, haftalık çalışma saatlerini 1475 SK gibi 45 saat olarak belirlemiş, fakat bir önceki kanun maddesinden ayrılarak, bu saatlerin çalışılan günlere eşit şekilde dağıtılması ilkesini değiştirmiştir. Maddenin 2. fıkrası uyarınca "tarafların anlaşması ile haftalık normal çalışma süresi, işyerlerinde haftanın çalışılan günlerine, günde on bir saati aşmamak koşulu ile farklı şekilde dağıtılabilir". Çalışma saati, bir çalışanın çalıştığı işletmede geçirdiği süreye denir (Cengiz, Temir, \& Erdin, 2011, s. 4). Fazla çalışma "haftalık 45 saati aşan çalışma olarak" tanımlamış ve bu bir haftalık ölçütü de yeterli görmeyip, 2 aylık süre için "denkleştirme esası" getirilmiştir (Çil, 2007, s. 58). Fazla çalışma uygulaması intiyacı toplum gereksinimlerini göz önünde bulundurularak ya da olağandışı bir olaya bağlı olarak ( teknik, ekonomik, afet vb.) artış azalış gösterebilir (Pınar, 2011, s. 10). Fazla çalışma, bir ülkenin istihdamını sadece sayısal (nicel) boyutunu irdelemek yeterli olmamakla birlikte manevi (nitel) boyutunu göz ardı edemeyiz. Bu yüzdendir ki, bir ülke ekonomisinde yapılan işlerin sayısal boyutu önemliyken, aynı zamanda yapılan işin toplumun bir üyesi olan çalışanın insanca yaşama, çalışma koşullarının uygun olması gibi imkânların sunulması son derece önemlidir. Kısacası bir ülke istihdamını artırabilmesi sadece nicel boyutla kalmayıp çalışanında ihtiyaçlarını, sosyal hayatını, beklentilerini göz önünde bulundurmalıdır (Kapar, 2007, s. 8).

\section{ìş/Aile Hayatı Çatışması}

İş-aile hayatı çatışması roller arası çatışmanın özel bir türü olarak kabul edilip (Efeoğlu, 2007, s. 238), bir grubun üyesi olmanın gereği olarak benimsenen rol ile bir ailenin üyesi olmanın gereği olarak benimsenen rol arasında bir uyumsuzluk olması sonucunda ortaya çıkmaktadır (Greenhaus ve Beutell, 1985, s.77). Bu çatışma, iş ile ilgili sorumluluklar, iş seyahatleri, fazla çalışma, çalışma saatleri ve evde yerine getirilmek zorunda kalınan iş yükümlülükleri gibi nedenlerle ortaya çıkabilmektedir (Hennessy, 2005, s. 2). Genel olarak iş-aile hayatı çatışması, kişinin iş ve aile hayatında yaşadıkları ile birlikte, bu iki alanın birbirlerine olan karşılıklı negatif etkilerini içermektedir (Akdoğan, 2013, s. 275). İ̧-aile çatışmasının birinci boyutunu oluşturan iş-aile çatışması (work-family conflict), bireyin işi ile ilgili üstlendiği rolün, ailesi ile ilgili sorumluluklarını yerine getirmesine engel olmasından dolayı meydana gelen çatışmadır. Buna işten aileye yönelik olan çatışma denir (Frone ve Cooper,1992, s. 728). Aile-iş çatışması (family-work conflict), aile içindeki sorumlulukların iş sorumlulukları ile karışması ya da aile sorumluluklarını iş sorumluluklarının önüne geçmesi durumunda yaşanmaktadır. Bu çatışma türü aileden işe yönelik çatışma türüdür (Arslan, 2012, s. 103). İ̧̧-aile çatışma kuramında da esas olarak çalışanların iş-aile hayatı çatışması yaşamalarının özünde söz konusu yaşam alanlarında farklı rollere girmesi değil bu rollerin gereklerini yerine getirme konusundaki zorlukların yattı̆̆ı kuramına dayanır (Kılıç, 2008, s. 243).

\section{İ̧̧ Hayatı/Özel Hayat Çatışmasının iş Talebi Ille ilişkisi}

Günümüzde mevcut çalışmalar inceleyerek, çalışanlara verilen standart saatin üzerinde olan uzun saatler çalışmak, çalışana olumsuz etkilere neden olacağını söylemek mümkündür. Özellikle batı tarafında yapılan birçok çalışmada, toplam çalışma süresinin ile "Iş-aile çatışması" ile pozitif bir ilişkiye sahip olduğunu ve "iş-aile çatışması" düzeyini etkileyebilecek güçlü bir faktörü olduğunu kanıtlamıştır (Sabil ve Marican, 2011 s. 206-207). Evli çiftlerin çalışma saatleri üzerinde odaklanan Presser (2000) yaptığı araştırmalarda çalışan evli kişilerin çalışıkları saat veya vardiyalı olup olmaması aile hayatını etkilediğini ortaya koymuştur. Hatta standart dışı çalışma programlarının, çalışan kişilerde ayrılma ve boşanma intimalini arttırdığını öne sürmüştür. Presser çalışma saatlerinin iş- aile hayatıyla ilintili olup önemli bir etken olduğunu vurgulamıştır (Presser, 2000, s. 93-94). Yoğun iş hayatı dolayısıyla stres yönetiminde yaşanan zorluklar kişinin yalnızca kariyerini değil, yakınlarıyla olan iletişimini de doğrudan etkiliyor. Yoğun iş hayatı; "Kendisine, ailesine ve sevdiklerine yeteri kadar zaman ayıramayan kişiler, dış çevreleriyle olan iletişimlerinde güçlükler yaşayabilmektedir. İ̧̧ hayatında yapıcı ve olumlu bir bakış açısı kazanmaya çalışmak, evde iş konuşmayarak iş ile ev arasındaki çizgileri belirlemek bu dengeyi kurmak konusunda yardımcı olacaktır." Bu olmadığı takdirde aile/ iş hayatı çatışması artacaktır (http://www.trthaber.com/haber/saglik/is-yogunlugu-sosyal-hayati-dogrudan-etkiliyor-309155.html erişim tarihi: 01.03.2018). İ̧̧ yoğunluğu iş-aile çatışmasını arttıran önemli etmenlerden biriyken, bunun yanında esnek olmayan çalışma saatleri, yoğun seyahat ve fazla mesai de iş/aile çatışmasını artırmaktadır (Greenhaus ve Beutel, 1985, s. 81). Açıklanan kuramsal bilgilere ve önceki alan araştırmaları bulgularına dayanarak aşağıdaki hipotezler önerilebilir. H1: İş talepleri bireylerin iş/ aile hayatı çatışmasını olumlu yönde etkilemektedir.

H1a: Bireylerin kendilerine yönelik değerlendirdikleri iş yükleri iş/aile hayatı çatışmalarını olumlu yönde etkilemektedir.

H1b: Bireylerin haftalık çalışma saatleri, deneyimledikleri iş/aile hayatı çatışmasını olumlu yönde etkilemektedir. 


\section{2. ÖRNEKLEM VE YÖNTEM}

Kolayda örnekleme yolu ile belirlenmiş hizmet ve üretim sektörlerinden 9 işletme de (ambalaj, paketleme, lojistik, makine üretim, ilaç, bankacılık, maden, gıda) uygulanmıştır. 303 beyaz ve mavi yakalı çalışan dönüt alınmıştır. Kantitatif (ölçekler ile oluşturulan envanter) yöntem uygulanmıştır. İş-aile çatışması ölçeği: Netenmeyer vd. (1996) tarafından geliştirilen 10 maddelik ölçek, $6^{\prime}$ ıı likert şeklinde yapılmıştır. İs-aile ve aile-iş olmak üzere iki alt boyutta değerlendirilmiştir iş̧ yoğunluğu: Karasek (1990) tarafından geliştirilen ölçeğin 4 maddesi, $\sigma^{\prime}$ Iı likert şeklinde yapıımışır. Çalışma saatleri: Haftalık çalışma saati (oransal ölçek) kullanılmıştır. Verilerin normallik dağııımı teşhisi: Histogram, çarpıklık ve basıklık katsayıları oluşturulup ölçeklerin güvenirlikleri cronbach alfa iç tutarlılık katsayısı ölçülmüştür. Ölçeklerin geçerlilikleri keşfedici faktör analizi ve Korelasyon ve Çoklu doğrusal regresyon analizleri yapılmıştır ve SPSS programı kullanıımıştır. Çalışma saati 129 kişi için elde edilen verilerle analiz yapılmıştır.

\section{ARAŞTIRMA BULGULARI}

Tablo 1: Güvenirlik Ve Geçerlilik İş-Özel Hayat Çatışması

\begin{tabular}{|c|c|c|c|c|c|}
\hline 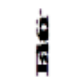 & Macldeler & $\begin{array}{l}\text { Falctör } \\
\text { Yuizleri }\end{array}$ & Ozdeğer & $\begin{array}{c}\text { Acrizlanan } \\
\text { Vanyans } \\
(0 \%)\end{array}$ & $\begin{array}{c}\text { ölcelz } \\
\text { güenilixliğgi }\end{array}$ \\
\hline 1 & 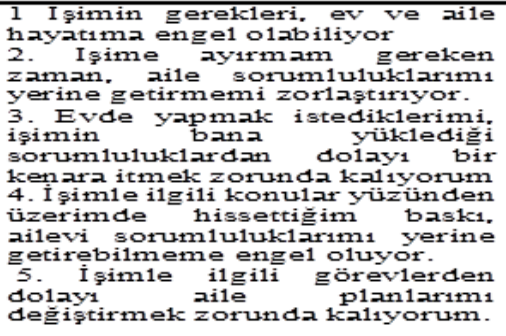 & $\begin{array}{l}0.867 \\
0.800 \\
0.793\end{array}$ & 4.709 & 30.985 & 0.905 \\
\hline 2 & 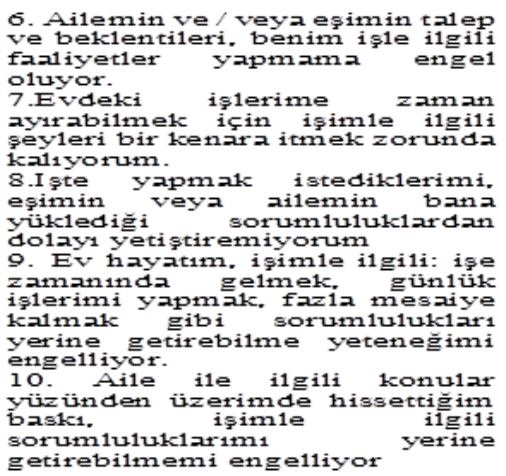 & 0.805 & 1.990 & 30.604 & 0.837 \\
\hline \multicolumn{2}{|c|}{ Top1 $\mathrm{am}$} & & & 67.589 & 0.877 \\
\hline \multicolumn{2}{|c|}{$\begin{array}{ll}\text { Kaiser-Mreyer-O11sin } \\
\text { Bart1etts Test of } \\
\text { Sphericity } & \text { dfpp } \\
& \text { Sig. }\end{array}$} & & $\begin{array}{l}0.858 \\
1072 \\
45 \\
0.00\end{array}$ & & \\
\hline
\end{tabular}

Tablo 2: Güvenirlik Ve Geçerlilik İş Yoğunluğu

\begin{tabular}{|c|c|c|c|c|c|}
\hline 竭 & Maddeler & $\begin{array}{l}\text { Faktör } \\
\text { Yükleri }\end{array}$ & Özdeğer & $\begin{array}{c}\text { Açklaman } \\
\text { Varyans } \\
(\%)\end{array}$ & $\underset{\text { güvenilcek }}{\ddot{\text { ölirliği }}}$ \\
\hline 1 & $\begin{array}{l}\text { 1. Mevcut iş yüküm oldukça } \\
\text { fazladır. } \\
\text { 2. Görevlerin etkin ve güvenli } \\
\text { bir şekilde yerine getirilmesi } \\
\text { için işte yetersiz insanlar var. } \\
\text { 3. Bana verilen işleri acele } \\
\text { etmeksizin yapmak için yeterli } \\
\text { zamanım yok. } \\
\text { 4. İş yüküm artmaya devam } \\
\text { ediyor }\end{array}$ & $\begin{array}{l}0,830 \\
0,591 \\
0,823 \\
0,886\end{array}$ & 2,499 & 62,468 & 0,789 \\
\hline \multicolumn{2}{|c|}{ Toplam } & & & 62,468 & 0,789 \\
\hline \multicolumn{2}{|c|}{$\begin{array}{ll}\text { Kaiser-Meyer-Olkin } \\
\text { Bartlett's Test of } \\
\text { Sphericity } & \text { dfprox. Chi-square } \\
& \text { Sig. }\end{array}$} & & $\begin{array}{l}0,758 \\
410,799 \\
6 \\
0,00\end{array}$ & & \\
\hline
\end{tabular}


Tablo 4: Değişkenler Arası Korelasyon

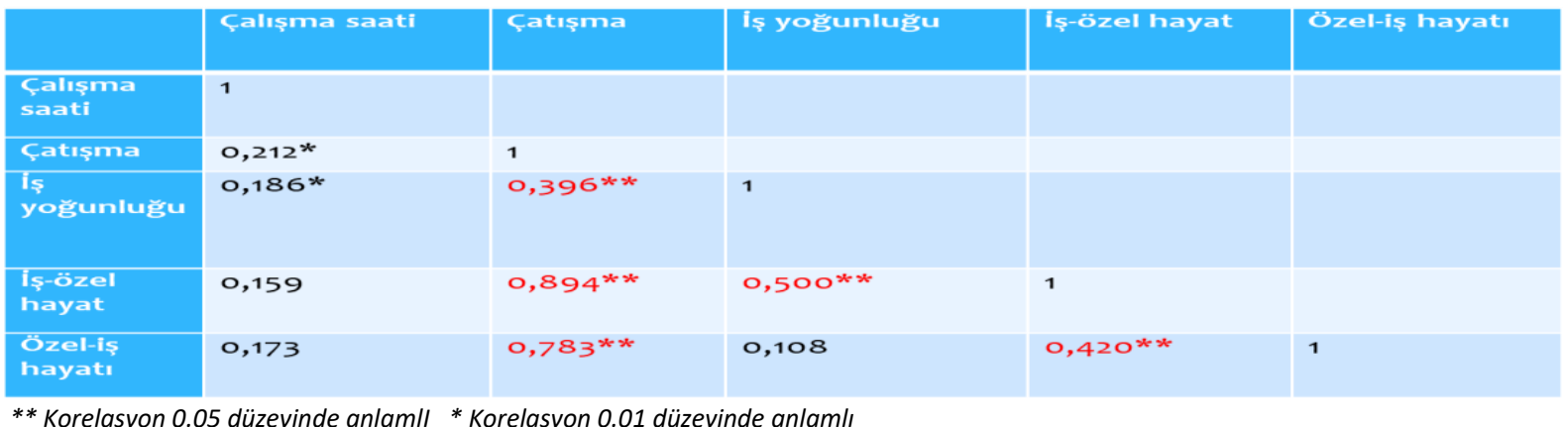

** Korelasyon 0.05 düzeyinde anlamll * Korelasyon 0.01 düzeyinde anlamlı

Tablo 5: Bağımsız Değişkenlerin Etkileri İş/Özel Hayat Çatışması

\begin{tabular}{|c|c|c|c|}
\hline \multirow[b]{2}{*}{ Bağımsız Değişkenler } & \multicolumn{3}{|c|}{$\begin{array}{c}\text { Bağımlı değişken: } \\
\text { İş-Özel hayat çatışması }\end{array}$} \\
\hline & Standart Beta & $\mathbf{T}$ & $\mathbf{P}$ \\
\hline İş yoğunluğu & 0,626 & 8,777 & $\mathrm{O,OOO}$ \\
\hline Çalışma saatleri & 0,036 & 0,497 & 0,620 \\
\hline $\mathbf{R}^{2}: 0,405$ & & Adj. $\mathbf{R}^{2}:$ & 0,395 \\
\hline
\end{tabular}

Tablo 6: Bağımsız Değişkenlerin Etkileri Özel /Iş̧ Hayat Çatışması

\begin{tabular}{|c|c|c|c|}
\hline \multirow[b]{2}{*}{ Bağımsız Değişkenler } & \multicolumn{3}{|c|}{$\begin{array}{c}\text { Bağımlı değişken: } \\
\text { Özel hayat-İş çatışması }\end{array}$} \\
\hline & Standart Beta & $\mathbf{T}$ & $\overline{\mathbf{P}}$ \\
\hline İş yoğunluğu & 0,296 & 3,337 & 0,001 \\
\hline Çalışma saatleri & 0,103 & 1,166 & 0,097 \\
\hline $\mathbf{R}^{2}: 0,112$ & & $\mathbf{A d j} \cdot \mathbf{R}^{2}:$ & 0,097 \\
\hline $\mathbf{F}: 7,514$ & & Anlamli & eğeri: $\mathrm{O}, \mathrm{O}$ \\
\hline
\end{tabular}

\section{SONUÇ VE TARTIŞMA}

H1a kabul, H1 b ret edilmiştir. Çalışma saatleri kişilerin iş-özel hayat çatışmaları üzerinde etkili olmadığı ortaya çıkmıştır. Çalışma saatleri kişilerin özel hayat-iş çatışmaları üzerinde etkili olmadığı ortaya çıkmıştır. Bunu sebebi olarak çalışanların beyan ettikleri sürenin üzerinde çalışmalarıdır. Bununla birlikte çalışanlar yasal çalışma saati sürelerini geçse de yasal çalışma süre aralığını belirtmeleridir. Son olarak beyaz yakalı çalışanların fazla çalışma ücretleri almamaktadırlar buna bağlı olarak saat beyanını ücrete endeksli görmedikleri için çalıştıkları saati sınırı aşan büyüklükte göstermemişlerdir. İş yoğunluğu, çatışmanın her iki türünü anlamlı olarak açıkladı. Yani bireylerin kendilerine yönelik değerlendirdikleri iş yoğunluğu iş/aile hayatı çatışmalarını olumlu yönde etkilemektedir.

\section{KAYNAKÇA}

Akdoğan, A. V. (2013). Psikolojik sermayenin performans üzerindeki etkisinde iş aile yayılımı ve psikolojik iyi oluşun etkisi. Atatürk Üniversitesi Sosyal Bilimler Enstitüsü Dergisi, cilt. 17, sayı. 1, s. 273-293.

Arslan, M. (2012). İş-aile ve aile-iş çatışmaların kadın çalışanların iş doyumları üzerindeki etkisi. Birey ve Toplum Dergisi, cilt. 2, sayı. 3, s. 99113.

Cam Kurt, M. Z. (2007). İşyeri çalişma sistemi ve işyeri fiziksel faktörlerinin iş kazalari üzerindeki etkisi. TÜHis İş Hukuku ve İktisat Dergisi, cilt. 21 , sayı. 1 s., $80-106$.

Cengiz, M., Temir, A., Erdin, B. (2011). Elli soruda İş Kanunu'nda çalışma süreleri. Çalışma Sosyal Güvenlik Bakanlığı (ÇSGB).

Çil, Ş. (2007). 4857 sayılı iş kanununa göre fazla çalışma ve fazla sürelerle çalışma. Çalışma ve Toplum, sayı.3, s. 57-79.

Yavuz, M. (13 Nisan 2017 Perşembe 15:30). İş yoğunluğu sosyal hayatı doğrudan etkiliyor. (http://www.trthaber.com/haber/saglik/isyogunlugu-sosyal-hayati-dogrudan-etkiliyor-309155.html erişim tarihi: 01.03.2018).

Efeoğlu, ì. V. (2007). İş-ahlak yaşam çatışmasının iş stresi, iş doyumu ve örgütsel bağılılk üzerindeki etkileri: ilaç sektöründe bir araştırma. Ç.Ü. Sosyal Bilimler Enstitüsü Dergisi, cilt. 16, sayı.2, s. 237-254. 
Frone, M. R. (1992). Prevalence of work-family conflict: are work and family boundraies asymmetrically permeable? Journal of Organizational Behavior, vol. 13, no. 7, p. 723-729.

Greenhaus, J. H. (1985). Sources of conflict between work and family roles. Academy of Management Review, vol. 10, p. 76-88.

Hennessy, K. (2005). Work-family conflict self-efficacy. A scale validation study. Masters, Of Arts, Universty of Maryland.

Karasek Jr, R. A. (1979). Job demands, job decision latitude, and mental strain: Implications for job redesign. Administrative science quarterly, vol. 24 , no. 2 , p. $285-308$.

Kapız, S. (2002). İş-aile yaşamı dengesi ve dengeye yönelik yeni bir yaklaşım: sınır teorisi. Dokuz Eylül Üniversitesi Sosyal Bilimler Enstitüsü Dergisi, cilt. 4. sayı. 3, s. 139-153.

Kılıç, K. (2008). Adana İli’ndeki özel sağlık merkezlerinde çalışan personellerin iş-aile yaşam çatışmasının örgütsel bağlılık, iş doyumu ve iş stresleri üzerine bir araştırma. Ç.Ü. Sosyal Bilimler Enstitüsü Dergisi, cilt. 17, sayı. 2, s. 241-254.

Netemeyer, R. B. (1996). Development and validation of work-family conflict and family-work conflict scales. Journal of Applied Psychology, vol. 20 , p. $400-409$

Presser, H. B. (2000). Nonstandard work schedules and marital instability. Journal of marriage and family, vol. 62, no. 1, p. 93-110.

Pınar, S. (2011). İnsan kaynaları yönetimi açısından fazla çalışma kavramı ve konuyla ilgili bir araştırma. İstanbul Üniversitesi Sosyal Bilimler Enstitüsü İ̧letme Anabilim Dalı İnsan Kaynakları Yönetimi Bilim Dalı Yüksek Lisans Tezi. İstanbul.

Sabil, S., Marican, S. (2011). Working hours, work-family conflict and work-family enrichment among professional women: a Malaysian case. Social Science and Humanity, vol. 5, p. 206-209.

Soysal, A. (2009). İ̧̧ yaşamında stres. Çimento İşveren Dergisi, cilt. 23, sayı. 3, s. 17-4. 